\title{
Assessment of changes in cardiopulmonary resuscitation practices and outcomes on 1005 victims of out-of-hospital cardiac arrest during the COVID-19 outbreak: registry-based study
}

Valentine Baert ${ }^{1,2}$, Deborah Jaeger ${ }^{3}$, Hervé Hubert ${ }^{1,2}$, Jean-Baptiste Lascarrou ${ }^{4,5}$, Guillaume Debaty ${ }^{6}$, Tahar Chouihed ${ }^{3}$, François Javaudin ${ }^{7,8^{*}}$ and on behalf of the GR-RéAC

\begin{abstract}
Background: The COVID-19 outbreak requires a permanent adaptation of practices. Cardiopulmonary resuscitation (CPR) is also involved and we evaluated these changes in the management of out-of-hospital cardiac arrest (OHCA).

Methods: OHCA of medical origins identified from the French National Cardiac Arrest Registry between March 1st and April 31st 2020 (COVID-19 period), were analysed. Different resuscitation characteristics were compared with the same period from the previous year (non-COVID-19 period).

Results: Overall, 1005 OHCA during the COVID-19 period and 1620 during the non-COVID-19 period were compared. During the COVID-19 period, bystanders and first aid providers initiated CPR less frequently (49.8\% versus 54.9\%; difference, -5.1 percentage points [95\% Cl, -9.1 to -1.2$]$; and $84.3 \%$ vs. $88.7 \%$; difference, -4.4 percentage points $[95 \% \mathrm{Cl},-7.1$ to -1.6$]$; respectively) as did mobile medical teams (67.3\% vs. $75.0 \%$; difference, 7.7 percentage points [95\% Cl, -11.3 to -4.1$])$. First aid providers used defibrillators less often (66.0\% vs. $74.1 \%$; difference, -8.2 percentage points $[95 \% \mathrm{Cl},-11.8$ to -4.6$]$ ). Return of spontaneous circulation (ROSC) and D30 survival were lower during the COVID-19 period (19.5\% vs. 25.3\%; difference, -5.8 percentage points [95\% Cl, -9.0 to -2.5$]$; and $2.8 \%$ vs. $6.4 \%$; difference, -3.6 percentage points [ $95 \% \mathrm{Cl},-5.2$ to -1.9 ]; respectively).
\end{abstract}

Conclusions: During the COVID-19 period, we observed a decrease in CPR initiation regardless of whether patients were suspected of SARS-CoV-2 infection or not. In the current atmosphere, it is important to communicate good resuscitation practices to avoid drastic and lasting reductions in survival rates after an OHCA.

Keywords: COVID-19, Registry, Out-of-hospital cardiac arrest, Resuscitation

\footnotetext{
* Correspondence: francois.javaudin@chu-nantes.fr

${ }^{7}$ Department of Emergency Medicine, University Hospital of Nantes, Nantes, France

${ }^{8}$ University of Nantes, Microbiotas Hosts Antibiotics and bacterial Resistances (MiHAR), University of Nantes, Nantes, France

Full list of author information is available at the end of the article
}

C C The Author(s). 2020 Open Access This article is licensed under a Creative Commons Attribution 4.0 International License, which permits use, sharing, adaptation, distribution and reproduction in any medium or format, as long as you give appropriate credit to the original author(s) and the source, provide a link to the Creative Commons licence, and indicate if changes were made. The images or other third party material in this article are included in the article's Creative Commons. licence, unless indicated otherwise in a credit line to the material. If material is not included in the article's Creative Commons licence and your intended use is not permitted by statutory regulation or exceeds the permitted use, you will need to obtain permission directly from the copyright holder. To view a copy of this licence, visit http://creativecommons.org/licenses/by/4.0/ The Creative Commons Public Domain Dedication waiver (http://creativecommons.org/publicdomain/zero/1.0/) applies to the data made available in this article, unless otherwise stated in a credit line to the data. 


\section{Introduction}

The current SARS-CoV-2 outbreak is leading to a reorganization of healthcare systems to limit as much as possible virus spread. Emergency medical systems must constantly adapt while coping with overloaded emergency departments, and severe working conditions [1]. The primary measures are based on population isolation, physical distancing and personal protective equipment (PPE) use. The virus is transmitted mainly by direct contact or droplets [2] from symptomatic or nonsymptomatic infected persons [3]. Outside the current viral outbreak, cardiopulmonary resuscitation (CPR) is not considered a frequent source of infectious disease transmission (estimated at $<1 / 200,000$ ) [4], however, close contact with a potentially infected subject, imposed by CPR, could be a source of SARS-CoV-2 contamination $[5,6]$. The resuscitation guidelines, in force since 2015, have therefore been adapted to this new situation; e.g., for basic life support (BLS), mouth-to-mouth ventilation in addition to chest compression are recommended to bystanders [7-9]. For advanced life support (ALS), bag-mask or supraglottic airway (SGA) ventilation are considered acceptable alternatives to tracheal intubation [10, 11]. Recently, updates have been issued, notably by the International Liaison Committee on Resuscitation (ILCOR) [12], the Emergency Cardiovascular Care Committee, and the American Heart Association [13]. Briefly, the main changes recommend that lay rescuers should consider chest compressions only (COCPR), except for children, and all life support providers should use PPE during resuscitation and favour early tracheal intubation to minimise aerosols. These changes, within the COVID-19 context, can impact the management of OHCA at each level (BLS and ALS). The purpose of our study was to compare the management of $\mathrm{OHCA}$ resuscitation by bystanders, first aid providers and mobile medical teams (MMT), between the COVID-19 outbreak period and a non-COVID-19 period.

\section{Methods}

\section{Study setting}

In France, the pre-hospital emergency medical system is two-tiered, with a fire department ambulance available for prompt intervention and BLS, and MMT for ALS [14]. The coordination of care for OHCA and other outof-hospital emergencies is under the responsibility of medical dispatch centres. All voluntaries MMT participating to the French OHCA registry (RéAC) use a specific intervention sheet for OHCA provided by the RéAC. The RéAC covers an at-risk population of about 20 million inhabitants. This RéAC recording form enables to collect patient data, times, care, and survival status. The RéAC form meets the requirements of the
French Emergency Medical System (EMS) organization, and is structured according to the universal Utstein style [15]. Data are reported in the secure RéAC database (www.registreac.org). During the outbreak period, RéAC users can record (database) if subjects are infected by COVID-19. A 30-day follow-up data collection after the OHCA or at the time of hospital discharge is performed and entered into the database. The whole functioning of the RéAC registry had previously been described [16].

\section{Study population and data}

Our comparative multicentre study used data from the French national OHCA registry (RéAC). We compared two cohorts of OHCA victims, the first corresponded to OHCA occurred between March 1st and April 31st 2020, corresponding to the COVID-19 outbreak period, and the second corresponding to OHCA occurred between March-April 2019, i.e. the non-COVID-19 period. Our inclusion criteria were: all medical OHCA according to the Utstein template [15]. Our exclusion criteria were: physical indication of death, patients with a known Do Not Attempt Resuscitation (DNAR) order, end of life patients, and traumatic drowning, overdose, asphyxia (external causes) and electrocution OHCA.

For COVID-19 affected-patients, probable or confirmed COVID-19 cases were identified in compliance with the World Health Organization (WHO) definition [17]. Hence, probable cases corresponded to a suspected case for whom testing could not be performed for any reason, or for whom testing for COVID-19 was inconclusive. In our context, patients with symptoms (fever associated with respiratory symptoms or symptoms suggestive of COVID-19 at the MMT physician discretion) and confirmed cases (COVID-19 laboratory confirmation) were aggregated to the same group: COVID-19 OHCA.

\section{Endpoints}

Our study was based on management comparisons during the COVID-19 and non-COVID-19 periods. Firstly, the determinants of resuscitation undertaken by bystanders (CPR initiation, type of CPR, use of a defibrillator), secondly, the description of BLS made by the first aid providers (timing, use of ventilation and defibrillator), and lastly, ALS details performed by the MMT (timing, initiation of ALS, administration of epinephrine and tracheal intubation). The other endpoints were return of spontaneous circulation (ROSC) and the survival 30 days after OHCA or at hospital discharge (D30 survival).

\section{Statistical analysis}

We described and compared baseline characteristics, BLS and ALS of the two patient cohorts (COVID-19 and 
non-COVID-19 period). In the COVID-19 period, we compared COVID-19 patients and non-COVID-19 patients. The quantitative variables were described as mean and standard deviations. The qualitative variables were described as frequencies. Bivariate analyses were assessed estimating the between-group difference and its 95\% confidence interval.

All statistical analyses were performed using SPSS software (version 25.0; IBM, Armonk, NY, USA). The threshold for statistical significance was set at $p<0.05$.

\section{Ethics}

This study was approved as a medical registry assessment by the French Advisory Committee on Information Processing in Health Research (CCTIRS), and by the French National Data Protection Commission (CNIL, authorisation number 910946). This study was approved as a medical registry assessment without the requirement for patient consent.

\section{Results}

\section{Patients}

During the study periods, 3629 subjects were recorded in the RéAC registry, 1375 were recorded in March and April 2020 (COVID-19 period), and 2254 in March and April 2019 (non-COVID-19 period). We excluded 591 victims of non-medical OHCA, 278 patients with physical indication of death at MMT arrival and 135 patients with "do no attempt resuscitation instructions" or in end of life. Hence, 2625 subjects were included; 1005 were recorded during the COVID-19 period (Fig. 1). Among the 1005 subjects in the COVID-19 period, 197 patients (19.6\%) were classified as COVID-19 OHCA.

\section{Baseline patient descriptions and comparisons}

As shown (Table 1), patient mean age was $68 \pm 17$ years and $75.5 \%$ of OHCA occurred at home. In terms of survival, $5.0 \%$ were alive at $\mathrm{D} 30$.

During the COVID-19 period, no demographic differences were observed regarding patient age, sex, and cardiovascular, respiratory or diabetes histories. However, ROSC and D30 survival were significantly lower (19.5\% vs. $25.3 \%$; difference, -5.8 percentage points [ $95 \% \mathrm{CI}$, 9.0 to -2.5 ]; and $2.8 \%$ vs. $6.4 \%$; difference, -3.6 percentage points [ $95 \% \mathrm{CI},-5.2$ to -1.9 ]; respectively).

\section{Basic life support}

In the total population, witnesses performed a BLS in $52.9 \%$ of cases, chest compression-only (CO-CPR) in $71.1 \%$ of cases, and chest compression with mouth to mouth (standard CPR, S-CPR) in $28.5 \%$ of cases (Table 2).

During the COVID-19 period, bystanders initiated BLS less often (49.8\% vs. $54.9 \%$; difference, -5.1 percentage points [ $95 \% \mathrm{CI},-9.1$ to -1.2$]$ ), and the no flow duration (time between collapse and CPR initiation) was longer (15 $\pm 18 \mathrm{~min}$ vs. $12 \pm 13 \mathrm{~min}$; mean difference, 3.0 [95\% CI, 1.8 to 4.2]). No differences were observed between the rate of CO-CPR and S-CPR, and the use of automated external defibrillators (AED).

During both study periods, first aid providers arrived in $12 \pm 10 \mathrm{~min}$ on OHCA scenes, and performed BLS in $87.0 \%$ of cases. A defibrillator was used in $71.0 \%$ of cases, and a shock was delivered to $17.3 \%$ of subjects.

During the COVID-19 period, the time between T0 (the call to emergency services) and first aid provider arrival was slightly longer $(12 \pm 11 \mathrm{~min}$ vs. $11 \pm 9 \mathrm{~min}$; mean difference, 1.0 [95\% CI, 0.0 to 2.0$]$ ). BLS was

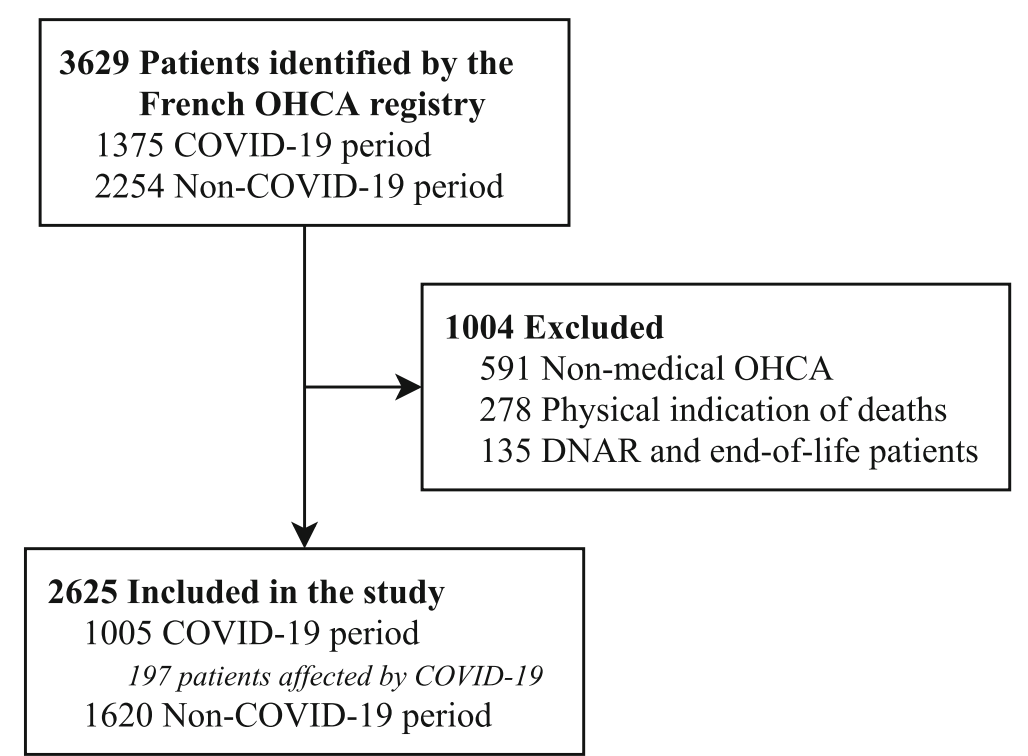

Fig. 1 Study flow chart. DNAR: Do Not Attempt Resuscitation, RéAC, French national out-of-hospital Cardiac Arrest Registry 
Table 1 Patient characteristics

\begin{tabular}{|c|c|c|c|c|}
\hline & $\begin{array}{l}\text { All patients } \\
N=2625\end{array}$ & $\begin{array}{l}\text { COVID-19 period } \\
N=1005\end{array}$ & $\begin{array}{l}\text { Non-COVID-19 period } \\
N=1620\end{array}$ & $p$-value \\
\hline Age, mean $\pm S D, y$ & $68 \pm 17$ & $68 \pm 17$ & $69 \pm 17$ & 0.137 \\
\hline Sex (Male), No./total (\%) & $1747 / 2625(66.6)$ & 676/1005 (67.3) & $1071 / 1620(66.1)$ & 0.552 \\
\hline \multicolumn{5}{|l|}{ Medical history, No./total (\%) } \\
\hline - Diabetes & $395 / 2625(15.0)$ & 156/1005 (15.5) & 239/1620 (14.8) & 0.613 \\
\hline - Cardiovascular & $1249 / 2625(47.6)$ & 478/1005 (47.6) & $771 / 1620(47.6)$ & 1.000 \\
\hline - Respiratory & 409/2625 (15.6) & 160/1005 (15.9) & 249/1620 (15.2) & 0.740 \\
\hline - Other & $746 / 2625(28.4)$ & $262 / 1005(26.1)$ & 484/1620 (29.9) & 0.036 \\
\hline - None & 155/2625 (5.9) & 46/1005 (4.6) & 109/1620 (6.7) & 0.026 \\
\hline OHCA location (home), No./total (\%) & 1975/2483 (75.5) & $819 / 971(84.4)$ & $1156 / 1512(76.5)$ & $<0.001$ \\
\hline OHCA cause, No./total (\%) & & & & 0.002 \\
\hline - Cardiac & $2001 / 2625(76.2)$ & $726 / 1005(72.2)$ & $1275 / 1620(78.7)$ & \\
\hline - Respiratory & $470 / 2625(17.9)$ & 210/1005 (20.9) & 260/1620 (16.0) & \\
\hline - Neurological & $44 / 2625(1.7)$ & 19/1005 (1.9) & $25 / 1620(1.5)$ & \\
\hline - Other medical cause & $110 / 2625(4.2)$ & $50 / 1005(5.0)$ & $60 / 1620(3.7)$ & \\
\hline Survival ROSC, No./total (\%) & $604 / 2615(23.1)$ & 195/999 (19.5) & 409/1616 (25.3) & 0.001 \\
\hline D30 Survival, No./total (\%) & $125 / 2483(5.1)$ & 26/937 (2.8) & $99 / 1546(6.4)$ & 0.001 \\
\hline
\end{tabular}

Table 2 BLS characteristics

\begin{tabular}{|c|c|c|c|c|}
\hline & $\begin{array}{l}\text { All patients } \\
N=2625\end{array}$ & $\begin{array}{l}\text { COVID-19 period } \\
N=1005\end{array}$ & $\begin{array}{l}\text { Non-COVID-19 period } \\
N=1620\end{array}$ & $p$-value \\
\hline \multicolumn{5}{|l|}{ By bystander } \\
\hline Bystander present (at collapse), No./total (\%) & $1683 / 2625(64.1)$ & $648 / 1005(64.5)$ & 1035/1620 (63.9) & 0.770 \\
\hline Immediate BLS, No./total No. (\%) & $928 / 2625(35.4)$ & $343 / 1005(34.1)$ & $585 / 1620(36.1)$ & 0.314 \\
\hline No Flow Duration, mean $\pm S D$, min ${ }^{a}$ & $13 \pm 15$ & $15 \pm 18$ & $12 \pm 13$ & $<0.001$ \\
\hline Bystander BLS, No./total (\%) & $1389 / 2625(52.9)$ & $500 / 1005(49.8)$ & $889 / 1620(54.9)$ & 0.011 \\
\hline CC only (CO-CPR) & $988 / 1389(71.1)$ & $362 / 500(72.4)$ & $626 / 889(70.4)$ & 0.075 \\
\hline$C C+M t M(S-C P R)$ & $396 / 1389(28.5)$ & $134 / 500(26.8)$ & $262 / 889(29.5)$ & \\
\hline MtM only & $5 / 1389(0.4)$ & $4 / 500(0.8)$ & $1 / 889(0.1)$ & \\
\hline AED use, No./total (\%) & $194 / 2625(7.4)$ & 75/1005 (7.5) & $119 / 1620(7.5)$ & 0.939 \\
\hline AED shock, No./total (\%) & $57 / 2625(2.2)$ & 21/1005 (2.1) & $36 / 1620(2.2)$ & 0.897 \\
\hline \multicolumn{5}{|l|}{ By first aid provider } \\
\hline Time between $\mathrm{TO}$ and first aid providers arrival, mean $\pm \mathrm{SD}$, min & $12 \pm 10$ & $12 \pm 11$ & $11 \pm 9$ & 0.010 \\
\hline First aid provider BLS, No./total (\%) & $2277 / 2618(87.0)$ & $845 / 1003(84.3)$ & 0.001 & 0.001 \\
\hline$-\mathrm{CC}$ & $2271 / 2278(99.6)$ & $842 / 846(99.5)$ & 1429/1432 (99.7) & 0.479 \\
\hline - Ventilation & 2131/2277 (93.6) & $795 / 845(94.1)$ & 1336/1432 (93.3) & 0.480 \\
\hline AED use, No./total (\%) & $1863 / 2625(71.0)$ & $662 / 1005(66.0)$ & $1200 / 1620(74.1)$ & $<0.001$ \\
\hline AED shock, No./total (\%) & $454 / 2625(17.3)$ & 154/1005 (15.3) & $300 / 1620(18.5)$ & 0.038 \\
\hline
\end{tabular}

Data are expressed as the number/total number (frequency \%) for qualitative variables or mean \pm standard deviation for quantitative variables $M M T$ mobile medical team, $B L S$ basic life support, $C C$ chest compressions, MtM mouth to mouth, CPR cardiopulmonary resuscitation, $A E D$ automated external defibrillator

a Time between collapse and CPR initiation 
attempted less frequently in the COVID-19 period group (84.3\% vs. $88.7 \%$; difference, -4.4 percentage points [95\% CI, -7.1 to -1.6$]$ ), and the defibrillator was less frequently used $(66.0 \%$ vs. $74.1 \%$; difference, -8.2 percentage points [ $95 \% \mathrm{CI},-11.8$ to -4.6$]$ ). However, when a BLS was implemented, no differences were observed for chest compression and bag-mask ventilation rates.

\section{Advanced life support}

The mean MMT arrival time was $22 \pm 15 \mathrm{~min}$, time to tracheal intubation was $28 \pm 13 \mathrm{~min}$, and time to adrenaline injection was $26 \pm 12 \mathrm{~min}$. ALS was started in $72.0 \%$ of cases (Table 3 ).

No differences between the two periods were observed for ALS timing or duration. ALS was less frequently implemented during the COVID-19 period $(67.3 \%$ vs. 75.0\%; difference, -7.7 percentage points [ $95 \% \mathrm{CI}$, 11.3 to -4.1$]$ ), and adrenaline was less frequently injected (61.8\% vs. 67.9\%; difference, -6.2 percentage points [ $95 \% \mathrm{CI},-10.0$ to -2.4$]$ ). The absence of injection routes implementation was more frequent during the COVID-19 period (34.2\% vs. $26.8 \%$; difference, 7.4 percentage points [ $95 \% \mathrm{CI}, 3.8$ to 11.1]). Tracheal intubation was less implemented (61.6\% vs. $69.1 \%$; difference, -7.5 percentage points [ $95 \% \mathrm{CI},-11.2$ to -3.7$]$ ).

\section{COVID-19 and OHCA victims}

Focusing on the COVID-19 period (between March 1st and April 31st 2020), when we compared COVID-19 victims of OHCA and non-COVID-19 patients (Table 4), no differences were observed for age, location of OHCA, bystander BLS, first aid provider of BLS and ALS implementation. However, COVID-19 patients were less likely to be male $(59.4 \%$ vs. $69.2 \%$; difference, -9.7 percentage points [95\% CI, -17.3 to -2.2$]$ ), present more respiratory histories (23.4\% vs. $14.1 \%$; difference, 9.2 percentage points [ $95 \% \mathrm{CI}, 2.9$ to 15.6$]$ ), and had a more respiratory aetiology of $\mathrm{OHCA}$ (56.9\% vs. 12.1\%; difference, 44.7 percentage points [95\% CI, 37.5 to 52.0]). In the COVID-19 OHCA group, no flow duration (time between OHCA and the first resuscitation) was longer (18 $\pm 22 \mathrm{~min}$ vs. $14 \pm 17 \mathrm{~min}$; mean difference, 4.0 [95\% CI, 1.2 to 6.8]), and the time between T0 and ROSC or death was also longer ( $48 \pm 27$ min vs. $43 \pm 23$ min; mean

Table 3 ALS characteristics

\begin{tabular}{|c|c|c|c|c|}
\hline & $\begin{array}{l}\text { All patients } \\
N=2625\end{array}$ & $\begin{array}{l}\text { COVID-19 period } \\
N=1005\end{array}$ & $\begin{array}{l}\text { Non-COVID-19 period } \\
N=1620\end{array}$ & $p$-value \\
\hline \multicolumn{5}{|l|}{ Times, mean $\pm S D$, min } \\
\hline Time between T0 and MMT arrival & $22 \pm 15$ & $23 \pm 18$ & $22 \pm 13$ & 0.461 \\
\hline Time between T0 and intubation & $28 \pm 13$ & $28 \pm 13$ & $28 \pm 13$ & 0.568 \\
\hline Time between T0 and epinephrine & $26 \pm 12$ & $27 \pm 13$ & $26 \pm 13$ & 0.400 \\
\hline Time between T0 and ROSC or death & $42 \pm 22$ & $44 \pm 24$ & $42 \pm 21$ & 0.342 \\
\hline \multicolumn{5}{|l|}{ Resuscitation practices } \\
\hline First recorded cardiac rhythm, No./total (\%) & & & & 0.226 \\
\hline - Asystole & $2041 / 2618(72.0)$ & 796/1003 (79.4) & $1245 / 1615(77.1)$ & \\
\hline - VF/pulseless VT & 232/2618 (8.8) & 87/1003 (8.7) & 145/1615 (9.0) & \\
\hline - PEA & 206/2618 (7.8) & 78/1003 (7.8) & 128/1615 (7.9) & \\
\hline - ROSC due to BLS & 139/2618 (5.3) & $42 / 1003(4.2)$ & $97 / 1615(6.0)$ & \\
\hline ALS implemented, No./total (\%) & $1891 / 2625(72.0)$ & $676 / 1005(67.3)$ & $1215 / 1620(75.0)$ & $<0.001$ \\
\hline Epinephrine injected, No./total (\%) & $1720 / 2623(65.6)$ & $620 / 1004(61.8)$ & $1100 / 1619(67.9)$ & 0.001 \\
\hline Total dose of epinephrine, mean $\pm S D$, mg & $5 \pm 4$ & $5 \pm 3$ & $5 \pm 4$ & 0.189 \\
\hline Injection route, No./total (\%) & & & & $<0.001$ \\
\hline - PIV & $1632 / 2625(62.2)$ & $582 / 1005(57.9)$ & 1050/1620 (64.8) & \\
\hline-10 & 199/2625 (7.6) & $71 / 1005(7.1)$ & $128 / 1620(7.9)$ & \\
\hline - Other & 16/2625 (0.6) & 8/1005 (0.8) & $8 / 1620(0.5)$ & \\
\hline - None & $778 / 2625$ (29.6) & $344 / 1005(34.2)$ & $434 / 1620(26.8)$ & \\
\hline Tracheal intubation, No./total (\%) & $1738 / 2625(66.2)$ & $619 / 1005(61.6)$ & $1119 / 1620(69.1)$ & $<0.001$ \\
\hline Impossible intubation, No./total (\%) & 46/1053 (4.4) & $15 / 375(4.0)$ & $31 / 678(4.6)$ & 0.754 \\
\hline Shock by AED, No./total (\%) & $394 / 2625(15.0)$ & $143 / 1005(14.2)$ & $251 / 1620(15.5)$ & 0.038 \\
\hline
\end{tabular}

Data are expressed as the number/total number (frequency \%) for qualitative variables or mean \pm standard deviation for quantitative variables $M M T$ mobile medical team, ROSC return of spontaneous circulation, VF/pulseless $V T$ ventricular fibrillation/pulseless tachycardia, $P E A$ pulseless electrical activity, $B L S$ basic life support, $A L S$ advanced life support, PIV peripheral intravenous access, $1 O$ intraosseous, AED automated external defibrillator 
Table 4 Comparisons between COVID-19 and non-COVID-19 patients during the COVID-19 period only (between March 1st and April 31st 2020)

\begin{tabular}{|c|c|c|c|}
\hline & $\begin{array}{l}\text { COVID-19 patients } \\
N=197\end{array}$ & $\begin{array}{l}\text { Non-COVID-19 patients } \\
N=808\end{array}$ & $p$-value \\
\hline Age, mean $\pm S D, y$ & $67 \pm 18$ & $69 \pm 16$ & 0.520 \\
\hline Sex (Male), No./total (\%) & 117/197 (59.4) & $559 / 808(69.2)$ & 0.011 \\
\hline \multicolumn{4}{|l|}{ Medical history, No./total (\%) } \\
\hline - Diabetes & 31/197 (15.7) & 125/808 (15.5) & 0.913 \\
\hline - Cardiovascular & 85/197 (43.1) & 393/808 (48.6) & 0.177 \\
\hline - Respiratory & 46/197 (23.4) & $114 / 808(14.1)$ & 0.002 \\
\hline - Other & $51 / 197(25.9)$ & $211 / 808(26.1)$ & 1.000 \\
\hline - None & 10/197 (5.1) & $36 / 808(4.5)$ & 0.704 \\
\hline OHCA location (home), No./total (\%) & 173/197 (87.8) & $646 / 774(83.5)$ & 0.153 \\
\hline OHCA cause, No./total (\%) & & & $<0.001$ \\
\hline - Cardiac & 67/197 (34.0) & 659/808 (81.6) & \\
\hline - Respiratory & 112/197 (56.9) & $98 / 808(12.1)$ & \\
\hline - Neurological & 2/197 (1.0) & 17/808 (2.1) & \\
\hline - Other medical cause & 16/197 (8.1) & $34 / 808(4.2)$ & \\
\hline Bystander presence, No./total (\%) & 126/197 (64.0) & $522 / 808(64.6)$ & 0.868 \\
\hline Immediate BLS, No./total (\%) ${ }^{\mathrm{a}}$ & 67/197 (34.0) & 276/808 (34.2) & 1.000 \\
\hline Bystander BLS, No./total (\%) & 99/197 (50.3) & 401/808 (49.6) & 0.937 \\
\hline First aid provider BLS, No./total (\%) & 162/197 (82.2) & $683 / 806(84.7)$ & 0.382 \\
\hline Times; No Flow duration, mean $\pm \mathrm{SD}$, $\min ^{\mathrm{b}}$ & $18 \pm 22$ & $14 \pm 17$ & 0.009 \\
\hline Time between T0 and first aid providers arrival, mean \pm SD, min & $16 \pm 18$ & $12 \pm 9$ & 0.095 \\
\hline Time between T0 and MMT arrival, mean \pm SD, min & $25 \pm 22$ & $23 \pm 17$ & 0.346 \\
\hline Time between TO and ROSC or death, mean \pm SD, min & $48 \pm 27$ & $43 \pm 23$ & 0.025 \\
\hline \multicolumn{4}{|l|}{ ALS } \\
\hline First recorded cardiac rhythm, No./total (\%) & & & 0.073 \\
\hline - Asystole & 163/197 (82.7) & $633 / 806(78.5)$ & \\
\hline - VF/pulseless VT & $8 / 197(4.1)$ & 79/806 (9.8) & \\
\hline - PEA & 18/197 (9.1) & $60 / 806(7.5)$ & \\
\hline - ROSC due to BLS & $8 / 197(4.1)$ & $34 / 806(4.2)$ & \\
\hline ALS implemented, No./total (\%) & 128/197 (65.0) & $548 / 808(67.8)$ & 0.447 \\
\hline ROSC, No./total (\%) & 34/196 (17.3) & 161/803 (20.0) & 0.423 \\
\hline D30 survival, No./total (\%) & 0/192 (0.0) & $26 / 745(3.5)$ & $<0.001$ \\
\hline
\end{tabular}

difference, 5.0 [95\% CI, 1.2 to 8.8$]$ ). No difference was observed regarding ROSC rate $(17.3 \%$ vs. $20.0 \%$; difference, -2.7 percentage points [ $95 \% \mathrm{CI},-8.7$ to 3.3$]$ ). Less survival 30 days after the OHCA was observed in COVID-19 patients (0.0\% vs. $3.5 \%$; difference, -3.5 percentage points [95\% CI, -5.1 to -1.2$]$ ). Respiratory causes were more frequent during this COVID-19 period (20.9\% vs. $16.0 \%$; difference, 4.8 percentage points [95\% CI, 1.8 to 7.9$])$.

\section{Discussion}

From a French OHCA prospective cohort, we assessed the impact of the COVID-19 outbreak on CPR practices (BLS and ALS). We observed that BLS and ALS initiation was less frequent during the COVID-19 period (whether the subjects were suspicious of COVID-19 or not). The ROSC rate was reduced by six points and D30 survival was halved during the COVID-19 period, when compared to the non- 
COVID-19 period, highlighting the potential impact of SARS-CoV-2 on CPR outcomes.

\section{BLS by bystanders}

During the COVID-19 outbreak period, we observed a lower rate of bystander CPR initiation. This could be explained by the fear of contracting SARS-CoV-2 infection. Scquizzatoa et al. warned of the need to initiate resuscitation as early as possible following an OHCA incident in Sydney, Australia, where bystander CPR was not initiated on a 60-year-old Chinese man for fear of infection with the coronavirus [18]. Indeed, initiating early CPR is key to successful outcomes $[19,20]$. For adults, CO-CPR appears to be a good alternative to standard CPR (including mouth-to-mouth ventilation) in this context. The meta-analyses of three randomised studies comparing S-CPR to CO-CPR, showed that CO-CPR was associated with improved survival $[21,22]$. Recent observational studies have shown either equivalent or improved outcomes of CO-CPR [23-25]. However, for children with OHCA, it would appear that S-CPR is associated with a better prognosis than CO-CPR [26]. The latest updated recommendations support this, i.e. COCPR for adults and S-CPR for children during the COVID-19 outbreak period [13]. To further reduce the viral transmission risk, it is suggested that the rescuer and the patient both wear masks or cloths if possible [13].

In the OHCA event, rapid access to a defibrillator is essential for an early ROSC and survival [27]. During the COVID-19 period, bystanders frequently used defibrillators despite the closure of some public places. Access to defibrillators has been maintained during this lockdown. Moreover, cardiac arrests occurred more frequently at home, where access to defibrillators were limited. The recent development of smartphone applications for locating defibrillators in public places and requesting citizen responders to provide CPR assistance on the scene may be one of the explanations for our observations [28]. For these inaccessibility events, it would be interesting to consider other strategies such as drone delivery $[29,30]$.

\section{BLS by first aid providers}

Bag-mask ventilation generates aerosols and therefore poses a high risk of contamination for first aid workers [31]. The use of a high efficiency particulate air (HEPA) filters between mask and bag, as well as two-hand bagmask ventilation techniques to ensure a tight seal have been promoted [13]. If MMT arrival is rapid, tracheal intubation must be performed, but if not, a simple passive oxygenation with non-rebreathing face mask (NRFM), covered by a surgical mask should be considered [13]. In our study, we observed less CPR initiation and less defibrillator use (i.e. just the application of the pads without necessarily shocking) by first aid providers during the COVID-19 period. Yet, there is no clear evidence that defibrillation generates aerosols [9]. Paradoxically, bag-mask ventilation which generates aerosols, was performed just as frequently in both COVID-19 and nonCOVID-19 periods.

\section{ALS by Mobile medical team}

Despite the COVID-19 outbreak impact on emergency medical systems, the arrival time of MMT was similar between the two periods. This agreed with an OHCA analysis in Paris, France, in March 2020 [32].

Tracheal intubation is frequently performed by MMT upon arrival at an OHCA [33]. The rate of tracheal intubation failure is low (approximately 2\%) when an airway is provided by an out-of-hospital emergency physician [34]. In spite of additional hygiene precautions (i.e. donning PPE and limiting personnel), we have not observed additional intubation failures or time delays during the COVID-19 period. Even if no delays were observed in time to intubation or epinephrine injection during the COVID-19 period, when compared to the non-COVID-19 period, we observed that the MMT implemented less injections or tracheal intubations, due to the fact that less ALS were initiated. Similarly, there was little use for intraosseous routes during both periods (approximately 8\%). However, it would appear that intraosseous routes may be easier for medical personnel in full protective gear [35]. This injection route is not widely used in France, and is not associated with a poorer prognosis, when compared to conventional peripheral venous routes [36].

Hence, during the COVID-19 period, patients received less resuscitation by MMT (ALS). An explanation for this could be that bystanders and first aid providers initiated less CPR, which lengthened no-flow durations in patients. This situation, no longer compatible with good outcomes, causing the MMT to stop resuscitation.

\section{Outcome}

Critically ill patients with SARS-CoV-2 pneumonia have poor survival rates [37]. When they experience cardiac arrest in hospital, the outcome is even worse. Indeed, D30 survival is approximately $3 \%$, and D30 with a good neurological outcome is less than 1\% [37]. In our series of cases with COVID-19, we observed less survivors 30 days following OHCA although we did not observe differences in BLS or ALS practices between COVID-19 OHCA and non-COVID-19 OHCA. We therefore observed a period effect explaining the differences in CPR. During the COVID-19 period, the rate of ROSC and D30 survival for all medical OHCA was very poor. The most compelling explanation was the decreased onset of 
resuscitation for both BLS and ALS, and decreased defibrillator use by first aid providers.

\section{Limitations}

Our study had several limitations. One was related to the RéAC registry. This registry is based on the voluntary participation of MMT, hence not all MMT participate in the registry. However, those MMT who participated were spread across France, and provided good overviews of French practices.

Another limitation involved the rapid execution of the study and the included data. Hence, the comparison of the number of patients included during the COVID-19 period and non-COVID-19 period should be performed with caution. Indeed, during this outbreak period, it was difficult for some MMT investigators to include patients in the RéAC registry, therefore all participating MMT did not include all their patients. Nevertheless, our aim was not to perform incidence calculations, therefore we included all registered OHCA (during the COVID-19 and non-COVID-19 period). Even if less patients were included in the COVID-19 period in our study, it was just a non-exhaustive cohort of patients, an increase of MMT French activity was observed as well as in Italy [38, 39]. This may have led to a selection bias, but our aim was to collect as much data as possible. Admittedly, this point limits the generalisability of the data, but does not preclude drawing at least tentative conclusions.

Moreover, the survival rate in this particular period, with all the cofounders associated with the COVID-19 cases should not be generalised. Factors external to the COVID-19 may have had an impact as well.

The final study limitation relates to the issue that some OHCAs may have been misclassified with regard to their COVID-19 status. Indeed, some of the "nonCOVID-19" cases may have been false negatives; moreover, we did not have access to post-mortem information. The limited access to COVID-19 testing in France may have led to the under-diagnosis of COVID-19 cases.

\section{Conclusions}

To conclude, during the COVID-19 period, we observed decreased initiation of CPR by bystanders and first aid providers for BLS, and decreased ALS by the MMT, regardless if subjects were infected with SARS-CoV-2 or not. ROSC rates and survival were also greatly reduced, even for non-COVID-19 subjects. It is now urgent and essential to communicate good resuscitation practices during this COVID-19 period, to avoid drastic and lasting reductions in survival rates after an OHCA.

\section{Abbreviations}

ALS: Advanced life support; BLS: Basic life support; CCTIRS: French Advisory Committee on Information Processing in Health Research; CNIL: French National Data Protection Commission; CO-CPR: Chest compressions only;
CPR: Cardiopulmonary resuscitation; EMS: Emergency Medical System; ILCOR: International Liaison Committee on Resuscitation; MMT: Mobile medical teams; NRFM: Non-rebreathing face mask; OHCA: Out-of-hospital cardiac arrest; PPE: Personal protective equipment; RéAC: French national OHCA registry; ROSC: Return of spontaneous circulation; S-CPR: Standard CPR; SGA: Supraglottic airway; WHO: World Health Organization

\section{Acknowledgments}

We thank especially for the inclusion of patients during the COVID period: Delphine Hugenschmitt, Thomas Bony, Clément Babin, Rudy Cohen, Natacha Ngoyi, Sébastien Jonquet, Terence Ahui, Tom Handwerk, Patrice Serre, Nadia Mansouri, François Revaux, Adèle Barbery, Mariane Ovtcharenko, Cécile Ursat, Lucie Ginoux, Cécile Bonhomme, Claire-Marie Weyer, Diego Abarrategui, Sophie Narcisse, Alice Conio, Hubert Courcoux, Coralie Chassin, Sylvain Thiriez, Benoit Jardel, Alain Guillon, Jessica Picot, Olivier Watrelot, Sébastien Mur, Nancy Gaillard, Fanny Larcher, Antoine Leroy, Céline Le Beuan, Carine Vanderstraeten, Frédéric Adnet, Jean-Marc Agostinucci, Steven Lagadec, Karim Tazarourte, Pierre-Yves Gueugniaud and Carlos El khoury. Gr-RéAC: For this study, GR-RéAC was composed by Drs: Abarrategui Diego, Adam Romain, Agostinucci Jean marc, Ahui Terence, Alcouffe Fabrice, Altervain Yohan, Amelon Francois-Xavier, Andre Fanny, Andriamirado Florian, Antouard Jerome, Arnaud Aurelie, Aubert Raphael, Avondo Aurelie, Babin Clement, Baina Anne, Ballet Celine, Barberis Christophe, Barbery Adele, Bardelay Romain, Bargain Philippe, Barukh Karen, Baudin Marine, Beaka Placido, Beayni Zaher, Belin Matthieu, Benoit Clement, Bertrand Philippe, Besnier Sylvie, Blain Stephane, Bonhomme Cecile, Bouilleau Guillem, Boulanger Bertrand, Bourg Arthur, Boursier Marion, Bouteloup Florent, Boutin Celia, Branche Fabienne, Bruneau Amandine, Busi Olivia, Caprini Pierre, Carle Olivier, Chabaud Asceline, Chantrel Gauthier, Chassin Coralie, Chatenet Guillaume, Chevrier Guillaume, Cissokho Khadidiatou, Clauw Emmelyne, Cohen Rudy, Colson Camille, Conio Alice, Constant Samuel, Costa Aurelie, Courcoux Hubert, Dattin Alix, De schlichting Marie alix, Decker Sandra, Dehouck Marc-Antoine, Deslais Benoit, Djebbar Lynda, Dubeaux Josephine, Dubois Camille, Duchier Caroline, Dumont Nathalie, Duperron Yann, Dussoulier Sebastien, Duval Benoit, Dyani Mohamed, Emonet Anne, Ferquel Martin, Fiani Nasri, Flambard Maud, Fleuchot Thomas, Foudi Lahcene, Frenais Regis, Fritsch Emmanuelle, Fuseau Celine, Fuster Patrick, Gaillard Nancy, Gay Julien, Gelin Emilie, Gentilhomme Angelie, Genuyt Benoit, Ginoux Lucie, Goulois Nathalie, Goulvin Virginie, Graux Cecile, Grave Eric, Grua David, Guenier Pierre-Alban, Guery Carole, Guillaumee Frederic, Guillet Aline, Guillon Alain, Guinard Sollweig, Guiot Olivier, Halbout Laurent, Hamdan David, Handwerk Tom, Harel David, Hebrard Manon, Hiller Pascale, Hoff Julie, Hoang Michael, Hugenschmitt Delphine, Jaeger Deborah, Jardel Benoit, Jauneau Charline, Javaudin Francois, Jeanmasson Yoann, Jeziorny Alexandre, Joliet Geraldine, Jonquet Sebastien, Kamara Mariam, Klimas Stephane, Laborne Francois xavier, Lacoste Julien, Lafitte Blandine, Lagadec Steven, LamarcheVadel Yacine, Lambert Julia, Lamothe Marion, Laot Melanie, Larcher Fanny, Lavielle Jeanne, Le beuan Celine, Le normand Thomas, Le pennetier Olivier, Lebail Antoine, Leclerc Maxence, Lepeve Alexandra, Leroy Antoine, Lespiauca Christine, Levrard Pascaline, Li crapi Raffaello, Longo Celine, Lorge Sarah, Loubert Richard, Lougnon Jean-Paul, Maigre Olivier, Majoufre Gwenaelle, Mansouri Nadia, Marc Jean-Baptiste, Maroteix Paul, Marrakchi Faycal, Massacrier Sylvie, Maurel Marion, Megard Marie fleur, Merle Heloise, Mesli Adil, Meunier Juliette, Miquelestorena Julie, Miranda Celine, Moine Linda, Montagnon Francois-Xavier, Morel Jean-Charles, Morel marechal Emanuel, Mur Sebastien, Muteaud Margaux, Narcisse Sophie, Nardy Jean ely, Naud Julien, Nave Sophie, Nenert Eloi, Ngoyi Natacha, Nguyen Kim, Nicolin Leandre, Nussbaum Camille, Oliveira Larissa, Ovtcharenko Mariane, Pancher Agathe, Parisot Sarah, Peixoto Brandon, Pernot Thomas, Petitdemange Olivia, Piboule Ludovic, Pic Daniel, Picot Jessica, Pinel Lauren, Plenier Cecile, Potriquier Stephane, Pradeau Catherine, Pretalli Jean-Baptiste, Prouve Christina, Prudor Florence, Quilliet Dominique, Raconnat Julien, Rallu Martin, Ramaherison Thierry, Remond Annabelle, Robart Jean-Christophe, Robert Helene, Rojas Jerome, Roucaud Nicolas, Roudiak Nathalie, Rouffilange Louis, Sanchez Caroline, Savu Alexandru, Sciacca Christelle, Scuotto Pierre, Sebai Salim, Serre Patrice, Simeon Isabelle, Simisdean Ciprian, Suhas Pauline, Sussat Myriam, Sylvie Roux, Tabary Romain, Tasei frederic, Tellier Eric, Theurey Odile, Thibaud Eric, Thiriez Sylvain, Trialoup Sarah laure, Trouvain Helene, Ursat Cecile, Vanderstraeten Carine, Vasseur Laurene, Vergne Muriel, Villain-Coquet Laurent, Watrelot Olivier, Weyer Claire marie, Zeribi Badia. 


\section{Authors' contributions}

VB and FJ contributed equally to this paper. VB and DJ are joint first authors. FJ, VB, HH and TC conceived and designed the study and drafted the manuscript. VB, FJ and HH computed statistics. DJ, JBL and GD brought critical revision to the manuscript for important intellectual content. All authors review and revised the manuscript and approves the final version.

\section{Funding}

The RéAC registry is supported by the French Society of Emergency Medicine (SFMU), a patient foundation - Fédération Française de Cardiologie, the Mutuelle Générale de l'Education Nationale (MGEN), the University of Lille and the Institute of Health Engineering of Lille.

\section{Availability of data and materials}

Data are available on request to the corresponding author.

\section{Ethics approval and consent to participate}

This study was approved as a medical registry assessment by the French Advisory Committee on Information Processing in Health Research (CCTIRS), and by the French National Data Protection Commission (CNIL, authorisation number; 910946). This study was approved as a medical registry assessment without the requirement for patient consent.

\section{Consent for publication}

Not applicable.

\section{Competing interests}

The authors declare that they have no competing interests.

\section{Author details}

'Univ. Lille, CHU Lille, ULR 2694 - METRICS, Évaluation des technologies de santé et des pratiques médicales, F-59000 Lille, France. ${ }^{2}$ French national out-of-hospital cardiac arrest registry, Registre électronique des Arrêts Cardiaques, Lille, France. ${ }^{3}$ Université de Lorraine, Inserm U1116; F-CRIN INI-CRCT, Emergency Department, University Hospital of Nancy, Nancy, France. ${ }^{4}$ Medical ICU, University Hospital Center, Nantes, France. ${ }^{5}$ the Paris Cardiovascular Research Center, INSERM Unité 970 \& the AfterROSC Network, Paris, France. ${ }^{6}$ Grenoble University Hospital, Grenoble, France. ${ }^{7}$ Department of Emergency Medicine, University Hospital of Nantes, Nantes, France. ${ }^{8}$ University of Nantes, Microbiotas Hosts Antibiotics and bacterial Resistances (MiHAR), University of Nantes, Nantes, France.

Received: 30 July 2020 Accepted: 24 November 2020

\section{Published online: 18 December 2020}

\section{References}

1. Garcia-Castrillo L, Petrino R, Leach R, et al. European society for emergency medicine position paper on emergency medical systems' response to COVID-19. Eur Jour Emerg Med. 2020;27(3):174-7.

2. Rothan HA, Byrareddy SN. The epidemiology and pathogenesis of coronavirus disease (COVID-19) outbreak. J Autoimmun. 2020;109:102433.

3. Bai $Y, Y a o L$, Wei $T$, et al. Presumed asymptomatic carrier transmission of COVID-19. JAMA. 2020:323:1406-7.

4. Mejicano GC, Maki DG. Infections acquired during cardiopulmonary resuscitation: estimating the risk and defining strategies for prevention. Ann Intern Med. 1998;129(10):813.

5. Christian MD, Loutfy M, McDonald LC, et al. Possible SARS coronavirus transmission during cardiopulmonary resuscitation. Emerg Infect Dis. 2004; 10(2):287.

6. Liu W, Tang F, Fang L-Q, et al. Risk factors for SARS infection among hospital healthcare workers in Beijing: a case control study. Tropical Med Int Health. 2009;14:52-9.

7. Berg RA, Hemphill R, Abella BS, et al. Part 5: adult basic life support: 2010 American Heart Association guidelines for cardiopulmonary resuscitation and emergency cardiovascular care. Circulation. 2010;122(18 suppl 3):S685-705.

8. Perkins GD, Handley AJ, Koster RW, et al. European resuscitation council guidelines for resuscitation 2015: section 2. Adult basic life support and automated external defibrillation. Resuscitation. 2015;95:81-99.

9. Couper K, Taylor-Phillips S, Grove A, et al. COVID-19 in cardiac arrest and infection risk to rescuers: a systematic review. Resuscitation. 2020;151:59-66.
10. Neumar RW, Otto CW, Link MS, et al. Part 8: adult advanced cardiovascula life support: 2010 American Heart Association guidelines for cardiopulmonary resuscitation and emergency cardiovascular care. Circulation. 2010;122(18 suppl 3):S729-67.

11. Soar J, Nolan JP, Böttiger BW, et al. Adult advanced life support section collaborators. European resuscitation council guidelines for resuscitation 2015: section 3. Adult advanced life support. Resuscitation. 2015;95:100-47.

12. Perkins GD, Morley PT, Nolan JP, et al. International liaison committee on resuscitation: COVID-19 consensus on science, treatment recommendations and task force insights. Resuscitation. 2020;151:145-7.

13. Edelson DP, Sasson C, Chan PS, et al. Interim Guidance for Basic and Advanced Life Support in Adults, Children, and Neonates With Suspected or Confirmed COVID-19: From the Emergency Cardiovascular Care Committee and Get With the Guidelines ${ }^{\circledR}$-Resuscitation Adult and Pediatric Task Forces of the American Heart Association in Collaboration with the American Academy of Pediatrics, American Association for Respiratory Care, American College of Emergency Physicians, The Society of Critical Care Anesthesiologists, and American Society of Anesthesiologists: Supporting Organizations: American Association of Critical Care Nurses and National EMS Physicians. Circulation. 2020;141(25):e933-43.

14. Javaudin F, Penverne Y, Montassier E. Organisation of prehospital care: the French experience. Eur J Emerg Med. 2020;27(6):404-5.

15. Perkins GD, Jacobs IG, Nadkarni VM, et al. Cardiac arrest and cardiopulmonary resuscitation outcome reports: update of the utstein resuscitation registry templates for out-of-hospital cardiac arrest: a statement for healthcare professionals from a task force of the International Liaison Committee on Resuscitation (American Heart Association, European Resuscitation Council, Australian and New Zealand Council on Resuscitation, Heart and Stroke Foundation of Canada, InterAmerican Heart Foundation, Resuscitation Council of Southern Africa, Resuscitation Council of Asia); and the American Heart Association Emergency Cardiovascular Care Committee and the Council on Cardiopulmonary, Critical Care, Perioperative and Resuscitation. Circulation. 2015;132(13):1286-300.

16. Hubert $H$, Tazarourte $K$, Wiel E, et al. Rationale, methodology, implementation, and first results of the French out-of-hospital cardiac arrest registry. Prehospital Emergency Care. 2014;18:511-9.

17. World Health Organization. Global surveillance for COVID-19 caused by human infection with COVID-19 virus: interim guidance, 2020. https://apps. who.int/iris/handle/10665/331506.

18. Scquizzato T, Olasveengen TM, Ristagno $G$, et al. The other side of novel coronavirus outbreak: fear of performing cardiopulmonary resuscitation. Resuscitation. 2020;150:92-3.

19. SOS-KANTO study group. Cardiopulmonary resuscitation by bystanders with chest compression only (SOS-KANTO): an observational study. Lancet. 2007; 369(9565):920-6.

20. Hasselqvist-Ax I, Riva G, Herlitz J, et al. Early cardiopulmonary resuscitation in out-of-hospital cardiac arrest. N Engl J Med. 2015:372(24):2307-15.

21. Zhan L, Yang LJ, Huang $Y$, et al. Continuous chest compression versus interrupted chest compression for cardiopulmonary resuscitation of nonasphyxial out-of-hospital cardiac arrest. Cochrane Database Syst Rev. 2017; 3(3):CD010134.

22. Hüpfl M, Selig HF, Nagele P. Chest-compression-only versus standard cardiopulmonary resuscitation: a meta-analysis. Lancet. 2010;376(9752): 1552-7.

23. Kitamura T, Kiyohara K, Nishiyama C, et al. Chest compression-only versus conventional cardiopulmonary resuscitation for bystander-witnessed out-ofhospital cardiac arrest of medical origin: a propensity score-matched cohort from 143,500 patients. Resuscitation. 2018;126:29-35.

24. Iwami T, Kitamura T, Kiyohara K, et al. Dissemination of chest compressiononly cardiopulmonary resuscitation and survival after out-of-hospital cardiac arrest. Circulation. 2015;132(5):415-22

25. Riva $G$, Ringh $M$, Jonsson $M$, et al. Survival in out-of-hospital cardiac arrest after standard cardiopulmonary resuscitation or chest compressions only before arrival of emergency medical services: Nationwide study during three guideline periods. Circulation. 2019;139:2600-9.

26. Zhang $X$, Zhang W, Wang $C$, et al. Chest-compression-only versus conventional cardiopulmonary resuscitation by bystanders for children with out-of-hospital cardiac arrest: a systematic review and meta-analysis. Resuscitation. 2019;134:81-90.

27. Kitamura T, Kiyohara K, Sakai T, et al. Public-access defibrillation and out-ofhospital cardiac arrest in Japan. N Engl J Med. 2016;375(17):1649-59. 
28. Valeriano A, Van Heer S, de Champlain F, Brooks S. Crowdsourcing to save lives: a scoping review of bystander alert technologies for out-of-hospital cardiac arrest. Resuscitation. 2020. https://doi.org/10.1016/j.resuscitation. 2020.10.035.

29. Boutilier JJ, Brooks SC, Janmohamed A, et al. Optimizing a drone network to deliver automated external defibrillators. Circulation. 2017:135(25):2454-65.

30. Claesson A, Bäckman A, Ringh M, et al. Time to delivery of an automated external defibrillator using a drone for simulated out-of-hospital cardiac arrests vs emergency medical services. JAMA. 2017;317(22):2332-4.

31. Tran $K$, Cimon $K$, Severn $M$, et al. Aerosol generating procedures and risk of transmission of acute respiratory infections to healthcare workers: a systematic review. PLoS One. 2012;7(4):e35797.

32. Lapostolle F, Agostinucci JM, Alhéritière $\mathrm{A}$, et al. Collateral consequences of COVID-19 epidemic in greater Paris. Resuscitation. 2020;151:6-7.

33. Javaudin F. Her S, Le Bastard $\mathrm{O}$, et al. Maximum value of end-tidal carbon dioxide concentrations during resuscitation as an indicator of return of spontaneous circulation in out-of-hospital cardiac arrest. Prehosp Emerg Care. 2020;24(4):478-84.

34. Jabre P, Penaloza A, Pinero D, et al. Effect of bag-mask ventilation vs endotracheal intubation during cardiopulmonary resuscitation on neurological outcome after out-of-hospital cardiorespiratory arrest: a randomized clinical trial. JAMA. 2018:319(8):779-87.

35. Smereka J, Szarpak L, Filipiak KJ, et al. Which intravascular access should we use in patients with suspected/confirmed COVID-19? Resuscitation. 2020; 151:8-9.

36. Baert V, Vilhelm C, Escutnaire J, et al. Intraosseous Versus Peripheral Intravenous Access During Out-of-Hospital Cardiac Arrest: a Comparison of 30-Day Survival and Neurological Outcome in the French National Registry. Cardiovasc Drugs Ther. 2020;34(2):189-97.

37. Shao F, Xu S, Ma X, et al. In-hospital cardiac arrest outcomes among patients with COVID-19 pneumonia in Wuhan, China. Resuscitation. 2020; 151:18-23.

38. Baldi E, Sechi GM, Mare C, et al. Out-of-hospital cardiac arrest during the Covid-19 outbreak in Italy. N Engl J Med. 2020;383(5):496-8.

39. Marijon E, Karam N, Jost D, et al. Out-of-hospital cardiac arrest during the COVID-19 pandemic in Paris, France: a population-based, observational study. Lancet Public Health. 2020;5(8):e437-43.

\section{Publisher's Note}

Springer Nature remains neutral with regard to jurisdictional claims in published maps and institutional affiliations.

Ready to submit your research? Choose BMC and benefit from:

- fast, convenient online submission

- thorough peer review by experienced researchers in your field

- rapid publication on acceptance

- support for research data, including large and complex data types

- gold Open Access which fosters wider collaboration and increased citations

- maximum visibility for your research: over $100 \mathrm{M}$ website views per year

At $\mathrm{BMC}$, research is always in progress.

Learn more biomedcentral.com/submissions 